\title{
Using Facility Condition Assessments to Identify Actions Related to Infrastructure
}

\author{
Kennedy F. Rubert \\ Jacobs Technology, Inc., Hampton, VA, 23681
}

\begin{abstract}
To support cost effective, quality research it is essential that laboratory and testing facilities are maintained in a continuous and reliable state of availability at all times. NASA Langley Research Center (LaRC) and its maintenance contractor, Jacobs Technology, Inc. Research Operations, Maintenance, and Engineering (ROME) group, are in the process of implementing a combined Facility Condition Assessment (FCA) and Reliability Centered Maintenance (RCM) program to improve asset management and overall reliability of testing equipment in facilities such as wind tunnels. Specific areas are being identified for improvement, the deferred maintenance cost is being estimated, and priority is being assigned against facilities where conditions have been allowed to deteriorate. This assessment serves to assist in determining where to commit available funds on the Center. RCM methodologies are being reviewed and enhanced to assure that appropriate preventive, predictive, and facilities/equipment acceptance techniques are incorporated to prolong lifecycle availability and assure reliability at minimum cost. The results from the program have been favorable, better enabling LaRC to manage assets prudently.
\end{abstract}

\section{Nomenclature}

psig $\quad=$ gauge pressure, pounds per square inch

\section{Introduction}

$\Lambda$ $\mathrm{S}$ with production methods in the industrial sector, performing good laboratory research in a timely manner requires reliable facilities. Unreliable equipment is not only frustrating to scientists and the research community, but also delays productivity for the Center, ultimately costing the taxpayer in terms of dollars and progress. In instances where wind tunnel resources have been committed to the commercial sector, delays can result in poor quality data, scheduling inadequacies, cost over-runs, and potential loss of business.

In reliability maintenance terms, equipment breakdowns are totally unacceptable. Unfortunately, long-term budget restraints over various political administrations have had a negative impact on at least a half dozen NASA research laboratories ${ }^{1}$. It is absolutely imperative that facilities reliability be improved dramatically in order to sustain the country's most vital asset of premier non-private sector aeronautics and space research.

Since funding limitations exist in virtually every business, any improvements must be executed in an effective and efficient manner. NASA Langley Research Center (LaRC) deploys the most industry proven approach to maintenance, which is Reliability Centered Maintenance (RCM). Although originally introduced in aviation, it has developed over the course of about fifty years and has been well received and practiced in a wide variety of areas including the manufacturing sector. NASA recognizes the benefits of RCM and has devoted considerable attention to establishing a program ${ }^{2}$ to implement this approach throughout the entire agency.

\section{FCA/RCM Program}

A Facility Condition Assessment (FCA) is a structured maintenance approach that dovetails well with RCM. It involves evaluating and documenting the condition of facility structures, systems and program equipment (or process machinery). FCA results in comparative condition indices, photographic documentation, descriptions of areas requiring repair and deferred maintenance (DM) cost estimates.

FCA is beneficial for planning and budgeting. It provides large operations a bird's eye view of the entire site condition. With this information, management can make informed decisions regarding funding and labor priorities. 
LaRC has chosen to include electrical substations and specific research support equipment (i.e. program equipment) under its definition of FCA facility data.

There are two approaches to performing FCAs, both of which are employed at LaRC:

- Mathematical modeling: This method is based on prior results of similar facilities and is relatively quick and effective.

- Detailed evaluation / "walk-through": This method requires more time and labor but provides better detail and more accurate Deferred Maintenance (DM) cost estimates.

Reliability Centered Maintenance (RCM) contains four key points that distinguish it from other methods: ${ }^{3}$

- Preservation of function.

- Identification of failure modes that can defeat function.

- Prioritization of function need (via failure modes).

- Applicability and effectiveness of maintenance tasks for the high priority failure modes.

Preserving function tends to focus the assessment on just what the facility or machine is intended to accomplish. A Failure Modes Effects Analysis (FMEA) is conducted to address possible failure modes and the priority. In many cases, seemingly minor issues can contribute to a functional failure, so the Pareto Principle is applied to illustrate the $20 \%$ that are most likely to cause $80 \%$ of the failures. This approach reduces the extent of preventative maintenance activity to high impact areas, thus reducing the associated cost.

Preventive Maintenance (PM)) and Predictive Maintenance (PdM) techniques are applied to address the pertinent failure modes. Since a PM can vary from minor adjustments to time consuming invasive activities, PdM is applied whenever possible; this minimizes cost and obviates the possibility of creating a problem while attempting to improve reliability. At LaRC, PM and PdM instructions are included in job plans, which are triggered by work orders. The periodicity of maintenance actions are established by the nature of the equipment, experience, and operating conditions.

The LaRC Facility Condition Assessments include the RCM element in a preliminary sense. Although PM and PdM programs (i.e. PT\&I) have been implemented at LaRC for some time, the FCA was deemed an excellent opportunity to review the situation, correct errors, and fine tune the maintenance operation. The FCA team consists of electrical and mechanical engineers as well as a variety of technicians.

During the winter of 2010, this team performed a combined FCA/RCM on LaRC's 14- by 22-Foot Subsonic Tunnel (Figure 1). This is an atmospheric, closed return tunnel with a test section $14.5 \mathrm{ft}$. high x $21.75 \mathrm{ft}$. wide x 50 $\mathrm{ft}$. long. In addition to the tunnel, drive equipment, and control room, there are associated offices and shop areas. The gross square footage area is a little less than 100,000. This survey required 803 labor hours for FCA and 678 for the RCM.

\section{A. FCA/RCM Process Steps}

Some steps can be performed in parallel while others must be conducted in sequence.

1. Schedule a meeting with the facility management to announce the study and seek cooperation.

2. Request that the facility perform a self evaluation (i.e. Facility Occupant Survey) and submit a list of any known issues that should be considered in the final report.

3. Perform a field inspection (i.e. "walk-through") of the facility to observe, photograph, and document conditions.

4. Update and correct errors and omissions in the Computerized Maintenance Management System (CMMS) database.

5. Examine and reorganize the asset

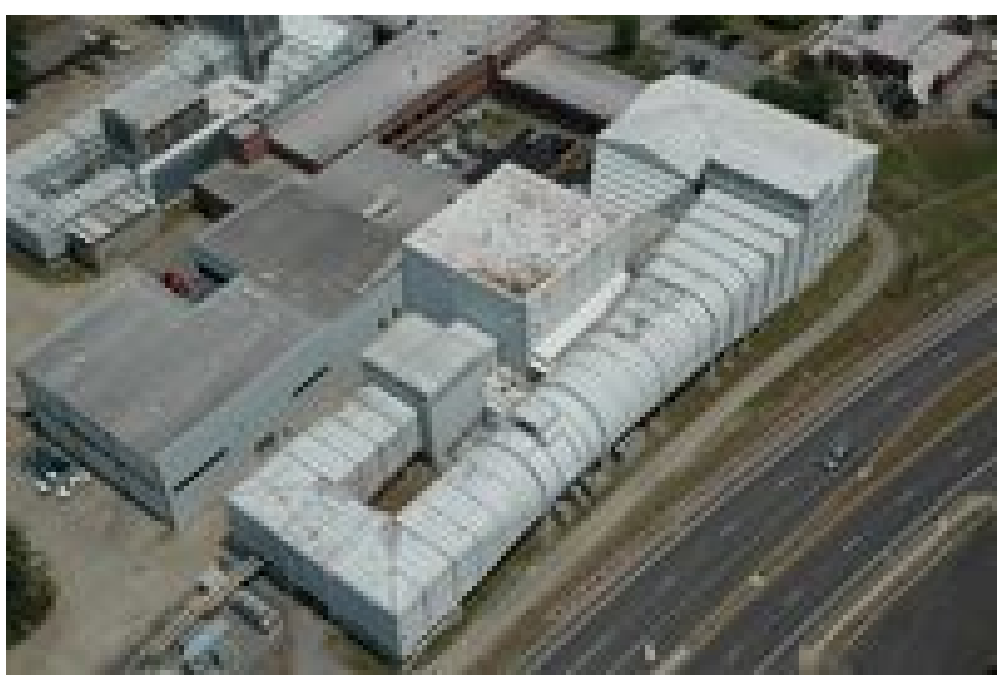

Figure 1. NASA Langley 14- by 22-Foot Subsonic Tunnel 
structure to reflect system grouping of the program machinery and processes.

6. Develop PM job plans as required for the facility to assure effective and cost efficient maintenance.

7. Prepare Deferred Maintenance (DM) scopes, which include order of magnitude cost estimates to restore the facility and program equipment to good condition.

8. $\quad$ Rate, calculate, and assign condition indexes.

9. Develop final report, review, and issue.

\section{B. FCA/RCM Application}

The introductory "kick-off" meeting is important for communicating the objective of the survey, the disruption level incurred while the task is being performed, information is expected from the customer, and identification of the evaluation personnel. Reporting the deficiencies of a facility can be disconcerting to the facility management as DM cost may be sufficient enough to imply blame. For example, the government may consequently entertain shutting down the operation or relocating it to a more cost attractive alternative. As a result, the inspection team may not always be received cordially.

Facility input is critical to detecting and addressing serious problems that might not be apparent to the inspection team. Even though the team may be knowledgeable, they are not experts at operating the program machinery and must rely on input from those closer to the operation. Those who work in a facility best understand the condition as well as issues that may not be otherwise obvious. Also, approved projects may already exist to correct deficiencies and do not need to be included in the DM cost. ROME utilizes a Facility Occupant Survey (Appendix 1), which is a structured approach to soliciting input.

Field inspections can require considerable time and effort. Not only must the structural and cosmetic condition of the facility be evaluated and documented, but wiring, plumbing, heating, and cooling must be addressed as well. Additionally, program equipment may require considerable time to research properly.

Currently the quality of original information entered in the LaRC CMMS is questionable for certain data sets due to system architecture, user consistency variables and available functionality. (Information may be missing or totally wrong. In some cases critical assets have not been captured.) Ensuring data quality requires checking the equipment in the field to assure assets are properly recorded, tagged, and entered correctly. It is not unusual to make 500 revisions to the CMMS database for a particular facility during the assessment.

This particular NASA Center dates back to 1917 when it was known as the National Advisory Committee on Aeronautics (NACA) Langley Memorial Aeronautical Laboratory. As a result, some of the facilities and equipment are aged and the process and instrument diagrams (P\&ID's) are either obsolete or do not exist; effort is being expended to update or develop P\&ID's as required. This serves to document the location of the various components within the process and provides the basis for efficient trouble shooting when problems occur. The absence of reliable P\&ID's is an industry wide dilemma typical of many older institutions. It is essential that documentation reflects the current status in order to support efficient and safe maintenance practices.

Work orders for PM's in our program are not consistently issued in a manner that promotes workplace efficiency. The site layout at LaRC requires maintenance personnel to travel among facilities or buildings in work vehicles. Hence, PM activities need to be grouped by location to minimize lost travel time.

The FCA/RCM team has been tasked with reorganizing the assets in systems to promote "system PMs" as opposed to individual assets and components. For example, when a main drive is removed from service to perform a "lift and flows" check on the fluid film bearings, other PM activities associated with the drive should be configured to be addressed simultaneously. Not only does this approach reduce overall downtime for maintenance but also reduces lost "wrench time" due to travel. In this case, the drive PM could be completed during one outage, eliminating interference with the production schedule during the remainder of the year.

Additionally, some operations contain multiple facilities within one area that share common services and utilities. Services and/or utilities typically consist of the following:

- Plant compressed air (110 psig).

- High pressure air (5,000 psig or less).

- High and low pressure steam.

- Electricity.

- Potable water.

- Additional (area specific).

In some cases, jet fuel, hydrogen, gaseous or liquid nitrogen, etc. may be included. NASA management is interested in knowing what facilities are impacted by the shutdown of any one particular service. Specifically, they want to know if they lose the entire operation, or simply one or two operations within the facility. This information 
may be known to some within ROME Facility Operations (FO), but it is not always available at upper management levels for efficient decision making. In the haste to implement the CMMS during the prior decade, many of the existing PM job plans lack enough specific direction and are of limited value to the technicians performing the work. Currently, these plans are being reauthored to provide detail and customization. Generic plans are also used and are maintained in a reference library.

In some cases, a plan can be attached to an asset with little to no customization. An example would be a conventional relief valve in which the primary difference among valves is the pressure relief set point and characteristics. The mechanism and PM approach to both the generic and specific versions, however, remains esentially the same. Conversely, a steam boiler or large power transmission coupling may require considerable customization depending on the type/size/complexity.

Another issue to consider is the extent of the instruction. Technicians under pressure to get the job done quickly may respond most favorably to brief instructions. On the other hand, engineers typically prefer more details and background information. Hence, the plans must be formatted to permit use in both areas. An example of a PM job plan is shown in Appendix 2.

The first step in developing a PM Job Plan is to perform a Failure Modes Effects Analysis (FMEA) for the machinery or process, then develop instructions that specifically address the identified potential failure modes. This reduces or eliminates the possibility of failure.

An acceptable job plan must be comprehensive and detailed to guide the technician in the specifics of the job. This means that quantitative data such as bolt torques, clearances, pressures, flows, voltages, currents, and acceptance criteria, etc. are essential. In accordance with NASA Reliability Centered Maintenance ${ }^{2}$ requirements, the condition of the equipment is evaluated using PdM techniques such as vibration, lubricant, or infrared analysis. If, the equipment does not meet the standards after PM is performed, corrective action must be taken before returning it service.

Developing Deferred Maintenance Scopes (DM's) is FCA-related and requires a broad knowledge base. Evaluations include the electric power network, building structures, foundations, roofing, HVAC, cosmetics, piping, and program machinery (drives, instrumentation, PLC's, etc.), etc. As a result, the task is divided between electrical and mechanical disciplines and assigned to assessment specialists accordingly.

With sufficient hands-on experience, it is generally not difficult to perform the overall condition assessment, unlike developing a cost estimate. Reference to commercial estimating guides, software, and handbooks is necessary. However, these references do not address program machinery, which may require time consuming research. If equipment is obsolete, the estimate must be based on conversion to state-of-the-art approach. Typical costs, based on a local market survey, are retained in a spreadsheet for quick reference. Performing work on government installations tends to cost more than the commercial sector because of additional safety requirements, documentation, etc. An example of a DM Scope is show in Appendix 3.

Rating of facilities and equipment is an FCA effort. Based on the condition, the facilities and program equipment are given scores ranging from "Excellent" with a numerical rating of 5 to "Bad" with a numerical rating of 1. Excellent is defined a "no work required" and Bad as "replacement required, major damage and safety concerns/issues". There are three intermediate condition levels which are defined on the FCA Summary. An example of a score sheet is shown in Appendix 4.

A final report is issued to NASA, as well as the facility customer, based on the outcomes of the assessment and data analysis. The final report involves reviewing the information, compiling the inputs into a comprehensive document, obtaining pertinent approvals, and uploading the information to an internal electronic storage library for data retention.

\section{Concluding Remarks}

The FCA/RCM program is beneficial as it provides an evaluation of an entire facility with sufficient detail to define and support development of specific engineering projects to address deficiencies. As a result, funding can be prioritized and confidently directed at areas that need attention.

The FCA/RCM program at LaRC has been developed simultaneously with field implementation. This means that the Center has realized numerous improvements for an internal use of the process while perfecting the application of techniques. It is expected that revisions will continue as the program evolves while the engineer and technician experience level increases. To date, ten facilities have undergone an FCA/RCM survey. The rate of progress is a function of the program equipment complexity, labor availability, funding and planning. Buildings tend to be relatively quick and turnkey. Process or program equipment can be slow, especially if it is obsolete or highly customized machinery. 
To expedite the process, LaRC initiated a request to contract a commercial FCA consultant to supplement the building assessment portion of the FCA program. Maintenance and Reliability Engineering (M\&RE) is expected to focus on program equipment and RCM during the process. 


\section{Appendix 1}

Survey Number: $\underline{001-2010}$ Required Return Date: $\underline{1 / 06 / 10}$

\section{FACILITY OCCUPANT SURVEY}

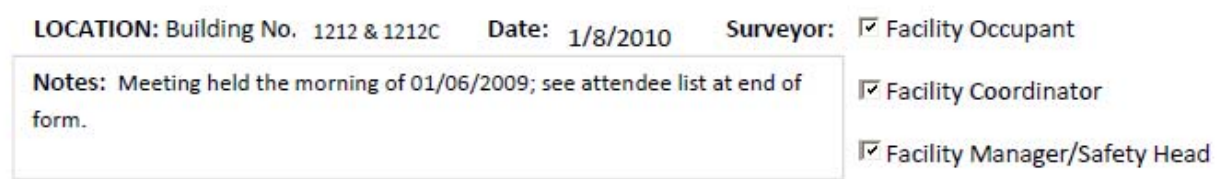

Purpose: This checklist will be used to collect the user's input on the facility's condition. Please be descriptive in your answers (i.e.: Location, problem description, etc), but do not be too specific in listing your information (i.e.: Bad ceiling tile in room 123). Your information will be used to help indentify deficiencies in the building systems and plan for their future repair or replacement.

There are a total of 9 building systems and 2 drive-specific systems used in the survey. They are listed below.

Building Systems:

1. Structure: Building foundation, walls, sidewalks, parking lots, etc.

2. Exterior: Exterior wall coatings, windows, doors and exterior sealants.

3. Roofing: Roof Coverings, openings, guttering and drains.

4. HVAC: Building heating, cooling balancing and control systems.

5. Electrical: Service and distribution, lighting, communications, security, fire and hazardous gas protection.

6. Plumbing: Water, sewer and fire protection piping, also piping for steam, natural gas, process gases and water distribution for specialty systems.

7. Conveying: Elevators, cranes, hoists and other lifts.

8. Interior Finishes: All interior finishes, all coverings and insulation, flooring, ceilings and interior doors.

9. Program Equipment: Collateral equipment installed for the facility to support testing or research.

Drive-specific systems (facility only):

1. Model Systems: Model mounting, checkout, ignition and fuel systems.

2. Model Handling Systems: Model sting and pedestal, nozzle and combustor handling cart.

Please grade the following systems and their sub-systems. If there is any specific information (repeated failures of a system or piece of equipment) you would like to be addressed, please note it in the comments section.

CONDITION SELECTIONS: 5 - Excellent, 4-Good, 3-Fair, 2-Poor, and 1-Bad

STRUCTURE:

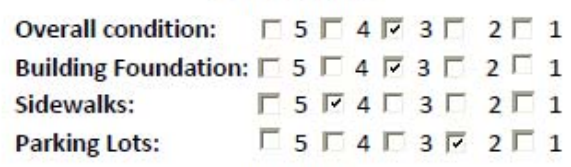

EXTERIOR:

Overall condition: $\Gamma 5 \Gamma 4 \Gamma 3 \Gamma 2 \Gamma 1$

Walls Covering: $\quad \Gamma 5 \Gamma 4 \Gamma 3 \Gamma 2 \Gamma 1$

Windows: $\quad \Gamma 5 \Gamma 4 \Gamma 3 \Gamma 2 \Gamma 1$

Exterior Walls: $\quad \Gamma_{5} \Gamma 4 \Gamma 3 \Gamma 2 \Gamma 1$

Exterior Doors: $\quad \Gamma 5 \Gamma 4 \Gamma_{3} \Gamma_{2} \Gamma{ }_{1}$

Exterior Sealants: $\Gamma 5 \Gamma 4 \Gamma 3 \Gamma 2 \Gamma 1$

\section{COMMENTS:}

\begin{tabular}{|l|}
\hline Significant parking lot damage, cracks \& pot holes 3.0 \\
\hline Minor cracks, settling separation of concrete pads / steps \\
\hline No significant issues; minor cracks \\
\hline Pot holes, cracks and equipment damage; rock road \\
\hline
\end{tabular}

Actual score 2.8 (Window Issues)

Paint, wall paper; general finish issues primarily in $1212 \mathrm{C}$

Broken latches, seal damage and discoloration

1212C Courtyard wall poor paint, corrosion

Finish and leaks underneath, wood door damage 1212

Water under walls under test section of $1212 \mathrm{C}$

CONDITION SELECTIONS: 5 - Excellent, 4-Good, 3-Fair, 2-Poor, and 1 - Bad 
ROOFING:

\begin{tabular}{|c|c|}
\hline Overall Condition: & $\Gamma_{5} \Gamma_{4} \Gamma_{3} \nabla_{2} \Gamma_{1}$ \\
\hline Roof Covering: & $\Gamma 5 \Gamma 4 \Gamma 3 \Gamma 2 \Gamma$ \\
\hline Opening: & $\Gamma_{5} \Gamma_{4} \nabla_{3} \Gamma_{2} \Gamma$ \\
\hline Gutters: & $\Gamma 5 \Gamma 4 \Gamma 3 \sqrt{ } 2 \Gamma$ \\
\hline Drains: & $\Gamma_{5} \Gamma_{4} \Gamma_{3} \nabla_{2} \Gamma$ \\
\hline
\end{tabular}

\section{HVAC:}

Overall Condition: $\Gamma_{5} \Gamma_{4} \Gamma_{3} \Gamma_{2} \Gamma_{1}$ Heating/unit heaters: $\Gamma 5 \Gamma 4 \Gamma 3 \sqrt{5} 2 \Gamma_{1}$ Air Conditioning: $\quad \Gamma_{5} \Gamma_{4} \Gamma_{3} \Gamma_{2} \Gamma_{1}$ Ventilation: $\quad \Gamma_{5} \Gamma_{4} \Gamma_{3} \Gamma_{2} \Gamma_{1}$ Control systems: $\quad \Gamma_{5} \Gamma_{4} \Gamma_{3} \Gamma_{2} \Gamma_{1}$ Dampers:

\section{COMMENTS:}

\begin{tabular}{|l|}
\hline (Actual 2.25) Gutter issues flashing cracks \\
\hline Leaks rooms 102, 103,104, 105 \& 116; flashing cracks \\
\hline Leaks around roof drains noted \\
\hline Gutters rotted out \\
\hline Full of sand and rocks in courtyard; vegetation growing \\
\hline
\end{tabular}

\begin{tabular}{|l|}
\hline (Actual 2.2) Severe control issues and equipment age. \\
\hline Poor control; fighting with AC; old systems \\
\hline Poor control systems, fighting with heat; old systems \\
\hline Older systems, mild to moderate corrosion \\
\hline Said to be totally ineffective \\
\hline Minor corrosion, aged \\
\hline
\end{tabular}

\section{ELECTRICAL:}

\begin{tabular}{|c|c|}
\hline Overall Condition: & $\Gamma 5 \Gamma 4 \sqrt{\Gamma} 3 \Gamma_{2} \Gamma_{1}$ \\
\hline Service \& Distrib.: & $\Gamma_{5} \Gamma_{4} \Gamma_{3} \Gamma_{2} \Gamma_{1}$ \\
\hline Lighting: & $\Gamma_{5} \Gamma_{4} \nabla_{3} \Gamma_{2} \Gamma_{1}$ \\
\hline Communications: & $\Gamma_{4} \Gamma_{3} \Gamma_{2} \Gamma_{1}$ \\
\hline Security: & $\Gamma_{4} \Gamma_{3} \Gamma_{2} \Gamma_{1}$ \\
\hline Fire Protection: & $\Gamma_{2} \Gamma_{1}$ \\
\hline Hazardous Gas: & $\Gamma_{4} \Gamma$ \\
\hline
\end{tabular}

\begin{tabular}{|l|}
\hline (Actual 3.8) Lighting issue in limited areas. \\
\hline Mixture of aged and newer equipment \\
\hline Some area out and not reliable; RM210-1212C \\
\hline New phone system literally \\
\hline No issues, very good condition \\
\hline No issues, very good condition \\
\hline Not applicable \\
\hline
\end{tabular}

\section{PLUMBING:}

\begin{tabular}{|c|c|c|}
\hline Overall Condition: & $\Gamma_{5} \Gamma_{4} \Gamma_{3} \Gamma_{2} \Gamma_{1}$ & (Actual 3.71) Sewage handling / smell issues. \\
\hline Water Piping: & $\Gamma_{5} \Gamma_{4} \Gamma_{3} \Gamma_{2} \Gamma_{1}$ & Hot water leaks $1^{\text {st }}$ floor of $1212 \mathrm{C}$ Pipe issues $1212-114$ \\
\hline Sewer Piping: & $\Gamma_{5} \Gamma_{4} \Gamma_{3} \Gamma_{2} \Gamma_{1}$ & Sewer smell in courtyard \& proximity of RM101/ 1212C \\
\hline Fire protection: & $\nabla_{5} \Gamma_{4} \Gamma_{3} \Gamma_{2} \Gamma_{1}$ & One leaking packing found, but generally good \\
\hline Piping: & $\Gamma_{5} \Gamma_{4} \Gamma_{3} \Gamma_{2} \Gamma_{1}$ & General piping no significant issues \\
\hline Steam and Natural: & $\Gamma_{5} \Gamma_{4} \Gamma_{3} \Gamma_{2} \Gamma_{1}$ & Steam leaks valves in limited areas \\
\hline Gas Piping: & $\Gamma_{5} \Gamma_{4} \Gamma_{3} \Gamma_{2} \Gamma_{1}$ & N/A \\
\hline Process Gas: & $\Gamma_{5} \Gamma_{4} \Gamma_{3} \Gamma_{2} \Gamma_{1}$ & N/A \\
\hline Heat Exchangers: & $\Gamma_{5} \Gamma_{4} \Gamma_{3} \Gamma_{2} \Gamma_{1}$ & No significant issues \\
\hline Piping Insulation: & $\Gamma_{5} \Gamma_{4} \Gamma_{3} \Gamma_{2} \Gamma_{1}$ & Small amounts missing / damage; insignificant amounts \\
\hline
\end{tabular}

\section{CONVEYING:}

\begin{tabular}{|c|c|c|}
\hline Overall Condition: & $\Gamma 5 \Gamma 4 『 3 \Gamma 2 \Gamma 1$ & (Actual 3.5)Mobile equipment needs maint. improvement \\
\hline Elevators: & $\Gamma 5 \Gamma 4 \Gamma_{3} \Gamma 2 \Gamma 1$ & Freight elevator out of service; reliability issues with other \\
\hline Cranes: & $\Gamma 5 \Gamma 4 \Gamma 3 \Gamma 2 \Gamma 1$ & Cranes said to be in very good condition \\
\hline Hoist: & $\Gamma_{5} \Gamma_{4} \Gamma_{3} \Gamma_{2} \Gamma_{1}$ & Hoist said to be in very good condition \\
\hline Other: & $\Gamma_{5} \Gamma_{4} \Gamma_{3} \Gamma_{2} \Gamma_{1}$ & Mobile equipment, maintenance issues \\
\hline
\end{tabular}

CONDITION SELECTIONS: 5 - Excellent, 4 -Good, 3 - Fair, 2 - Poor, and 1 - Bad 


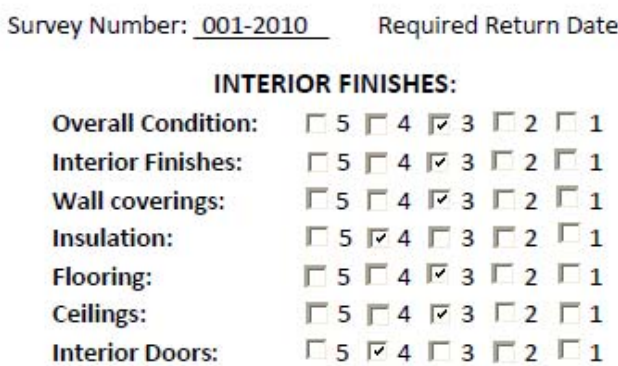

COMMENTS:

\begin{tabular}{|l|}
\hline (Actual 3.33) Door 101/101A, (1212C) wall paper \& paint \\
\hline Paint \& minor damage 1212/1212C \\
\hline Wall paper peal \\
\hline No know issues \\
\hline Some aged minor damage \\
\hline Minor staining, damage and missing tiles \\
\hline 101-101A Door hinge issues (1212C) \\
\hline
\end{tabular}

PROGRAM EQUIPMENT:

\begin{tabular}{|c|c|c|}
\hline Overall Condition: & $\Gamma 5 \Gamma 4 \Gamma 3 \Gamma 2 \Gamma 1$ & (Actual 3.2) Oil interlock, vibration \& breaker ind. light \\
\hline Cooling/Heating \& & & Aged equipment, minimal equipment \\
\hline Vent Systems: & $\Gamma_{5} \Gamma_{4} \Gamma_{3} \Gamma_{2} \Gamma_{1}$ & \\
\hline Lubrication Systems: & $\Gamma_{5} \Gamma_{4} \Gamma_{3} \Gamma_{2} \Gamma_{1}$ & Leaks and vibration issues; oil heating interlock issues \\
\hline Hydraulic Systems: & $\Gamma_{5} \Gamma_{4} \Gamma_{3} \Gamma_{2} \Gamma_{1}$ & Have had problems with lifts \\
\hline Process Gas Systems: & $\Gamma_{5} \Gamma_{4} \Gamma_{3} \Gamma_{2} \Gamma_{1}$ & N/A \\
\hline Drive Systems: & $\Gamma_{5} \Gamma_{4} \Gamma_{3} \Gamma_{2} \Gamma_{1}$ & M/G Set Grounding Issues; project to correct \\
\hline Control systems: & $\Gamma_{5} \Gamma_{4} \Gamma_{3} \Gamma_{2} \Gamma_{1}$ & Said to be in very good condition, breaker light issues \\
\hline
\end{tabular}

MODEL SYSTEMS:

\begin{tabular}{|c|c|}
\hline Overall Condition: $\quad \Gamma 5 \Gamma 4 \Gamma 3 \Gamma 2 \Gamma 1$ & (Actual 3.0) Model mounting verification of fit; facility. \\
\hline Model Mount'g Equip.: $\Gamma_{5} \Gamma_{4} \Gamma_{3} \Gamma_{2} \Gamma_{1}$ & Model mounting verification of fit; facility. \\
\hline Model Checkout Equip.: $\Gamma 5 \Gamma 4 \Gamma$ & No issues discussed \\
\hline Model Fuel Systems: $\Gamma_{5} \Gamma_{4} \Gamma_{3} \Gamma_{2} \Gamma_{1}$ & N/A \\
\hline
\end{tabular}

MODEL HANDLING SYSTEMS:

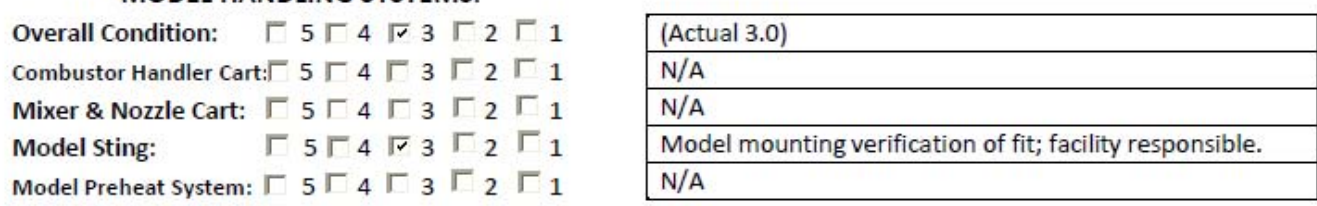




\section{FUTURE UPGRADES:}

If there is a planned future upgrade to building or equipment systems please let us know. This could make a difference in our recommendations for future deferred maintenance plans.

Installation of propane delivery system.

No. 1 Air Station relocation

Control systems on three (3) model carts upgrade

Construct blades replacement set and 2 spares; 1.5 million

Fabrication building for storage of blades (15 million estimated)

B1212 getting addition on front of facility

Study to turn machine rooms into office space B1212

Flow Collector damaged jack screw / associated fasteners; etc., replacement in test cell

\section{CLOSING COMMENTS:}

If there is any additional information that you feel would be helpful, please include it in the space below.

\begin{tabular}{l} 
If there is any additional information that you feel would be helpful, please include it in the space below. \\
\begin{tabular}{|l|}
\hline \\
\hline
\end{tabular} \\
\hline
\end{tabular}

Kick-off Meeting Attendees 


\section{Appendix 2}

\section{ROM E}

\section{Maintenance \& Reliability Engineering}

Job Plan RLF-02, Relief Valve, 0xygen Clean

\section{Procedure Description:}
A. Special Handling
B. Visual inspection
C. Recertification

"Oxygen Clean" is an expression that means to remove, transport, test, clean, store, and install the device in a manner that assures sufficient cleanliness for use in an oxygen rich environment. Due to serious safety and process ramifications, it is absolutely imperative that the cleanliness procedures be followed without exception. All personnel involved in the process shall receive training and be properly certified to perform the work.

\section{Craft \& Labor Estimates:}

- Mechanic or pipefitter: 2 hours

- Component Verification Lab technician: $1 / 2$ - 4 hours (depending on size, pressure rating, and quantity)

- Oxygen Cleaning: 4 hours (it is recommended that devices be processed in batches to reduce the cost)

\section{References:}

- LPR 1710.42, Safety Program for the Maintenance of Ground-based Pressure Vessels and Pressurized Systems

- NASA-STD-8719.17, NASA Requirements for Ground-Based Pressure Vessels and Pressurized Systems (PVS)

- LPR 1740.5, Procedures for Cleaning of Systems and Equipment for Oxygen Service

- NASA Kennedy Space Center 79K09560 and 79K09561, Sealant and Lubricants

- NASA LPR 1710.10 and ROME Policy 01-02-GM, lockout/tagout

- Flexitallic Gasket Design Criteria Manual (use only for bolt torque information)

- Garlock Engineered Gasketing Manual (use only for bolt torque information)

\section{Caution / Warning Summary:}

- Do not use Flexitallic or Garlock sealing products as these may contain graphite. Use only the sealing materials specified in the Air Products valve specifications.

- Exposure to process fluid or gas may require special PPE.

\section{Safety and Additional PPE:}

- Perform lockout/tagout in accordance with NASA LPR 1710.10 and ROME Policy 01-02-GM. Be sure to relieve system pressure.

- Be alert to the possibility of thermal burns from accidental loss of liquid. 
- Be alert to the possibility of exposure to toxic substances. See MSDS as required.

\section{Materials:}

- Applicable gasket

- Teflon tape

\section{Tools:}

- Mechanic's standard hand tools

- Fish tape

- Borescope (also boroscope)

\section{Preliminary:}

- Coordinate all work with facility coordinator and determine any restrictions or other hazards.

- Consider the need for rigging support.

- Fabricate metallic blanks (aluminum is okay) to cover the exposed pipe openings on the relief device and piping from whence it has been removed.

- Ensure equipment/component identification (name and/or number) is legible and securely affixed to equipment. Repair/replace these as necessary

- If necessary, arrange for the Pressure Systems Recertification Group to provide borescope services.

\section{Procedure:}

A. Visual Inspection

A01 Inspect for evidence of leakage past valve seat.

A02 Inspect for evidence of leakage from process connection.

A03 Inspect the identification tags for legibility.

B. Recertification

B01 Perform Lock Out Tag Out (LOTO per NASA LPR 1710.10 and ROME Policy 01-02-

GM) and relieve system pressure. Do not trust pressure gauges.

B02 Remove the relief valve. Crack side of flange away from you first to check for the possibility of pressure on system.

B03 Immediately seal the openings on the relief device with a layer of polyethylene film (Aclar 22a or equivalent available at LaRC clean room) and PVC tape in accordance with NASA LPR 1740.5 to prevent dirt entry. Install a metal blank over the Aclar 22a and place another layer of Aclar 22a on top of that. Seal with PVC tape.

B04 Immediately seal the exposed ends of the piping with polyethylene film (Aclar 22a or equivalent available at LaRC clean room) and PVC tape in accordance with NASA 
LPR 1740.5 to prevent dirt entry. Install a metal blank over the Aclar 22a and place another layer of Aclar 22a on top of that. Seal with PVC tape.

B05 Transport the relief valve to the Component Verification Laboratory for testing and recertification.

B06 Where the device has been properly sealed, the Component Verification Laboratory may elect to perform the testing and calibration on a dedicated test station that maintains oxygen clean conditions. Work performed in this manner does not require final cleaning and this step may be omitted. Upon testing and certification of the device, the openings shall be sealed in polyethylene film (Aclar 22a or equivalent available at LaRC clean room) with PVC tape in accordance with NASA LPR 1740.5. Install a metal blank over the Aclar 22a and place another layer of Aclar 22a on top of that. Seal with PVC tape.

B07 Where oxygen clean conditions have been violated during testing and certification, the device shall be transported to the Oxygen Cleaning Facility for cleaning, particulate measurement, sealing, documentation, and labeling in accordance with NASA LPR 1740.5.

B08 Verify that the vent line is unobstructed. Use of fish tape or a borescope may be required. Remove all traces of oil and dirt from the tooling prior to use.

B09 Check the recertified valve for a new tag with valve number, set pressure, and current date.

B10 Reinstall the valve using a new gasket or appropriate pipe thread sealant. Never use a petroleum based (oil) lubricant in oxygen applications.

B11 Torque flange bolts to appropriate values recommended for the gasket material. Refer to the OEM gasket design criteria manual or equivalent for the torque pattern and stages.

\section{Inspection Data:}

- On the work order, document the condition of equipment and work performed, then forward to the facility coordinator and CMMS coordinator for data retention.

- For any steps in this procedure, record unsatisfactory conditions on work order and report them to supervisor.

\section{Engineer's Notes:}

In accordance with NASA-STD-8719.17A, sections 4.10.1.5.2 through 4.10.1.5.2.3, the inspection frequencies are as follows:

- Gas systems above 200 psig MAWP-3 years

- Pressure Safety Valves (PSV's) in combination with rupture disks-5 years

- Category M, corrosive, flammable, or toxic fluid systems-2 years

- All others in accordance with Center procedures, but no more than 5 years. Check with the Standard Practice Engineer (SPE) for recommendations. 


\section{Maintenance \& Reliability Engineering} Job Plan RLF-02, Relief Valve, 0xygen Clean

Materials to prevent thread seizing, galling, and for sealing shall be in accordance with Kennedy Space Center 79K09560 and 79K09561. Never use petroleum (oil) based sealants or lubricants in the presence of oxygen. Some examples for use in both liquid and gaseous oxygen include:

- Lubricants: Krytox 143AC, Krytox 240AC, Tribolube F195, Tribolube 16

- Gaskets: Viton, Teflon, Kel-F

- Thread sealants: Teflon tape manufactured from pure virgin Teflon

Packaging:

- Polyethylene film shall conform to L-P-378, Type II in accordance with NASA LPR 1740.5. Aclar 22A, high density polychlorotrifluorethylene (CTFE) film, manufactured by Honeywell is used by the NASA LaRC Clean Room. Borrow the amount needed from this facility and provide a charge code for replacement. Do not store excess in a non-clean environment.

- Sealing tape shall be polyvinylchloride (PVC) in accordance with PPP-T-66, Type I, Class B.

\section{Approvals:}

\begin{tabular}{|l|l|l|l|l|}
\hline \multicolumn{1}{|c|}{ Approved By } & \multicolumn{1}{|c|}{ Printed Name } & Title & Signature & Date \\
\hline Author & K. F. Rubert & Senior Engineer & & \\
\hline M\&RE Manager & M.H. Sawyer & & & \\
\hline Technical Review & J.R. Wilson & & & \\
\hline SPE & Carlos Perez-Ramos & & & \\
\hline
\end{tabular}




\section{Appendix 3}

Task \#: АM31CK0-01107202-00

Date: January 12, 2010

Building \#: B1212C

Work Type: Deferred Maintenance

Program Equipment Repairs

Scoping Estimate: $\$ 58,000$

Recommended Year of Performance: 2011

\section{A: Summary}

- The existing shed over the main drive lubrication pump and reservoir is not large enough to keep rain water from filling the oil catch pan. As a result, the collected water has to be disposed of as waste oil, increasing the cost of operation. The roof needs to be extended.

- The current practice is to install filter media across the air louvers in the tower. There is no safe way to access the louvers at top of the tower when changing the filter material. A catwalk needs to be installed to make the job safer. The design is currently in progress.

B: General

This building is primarily used as a sub-sonic testing facility and navigation center.

C: Equipment

See Task Activity

C: Task Activity

a. Design and build new pump system shed.

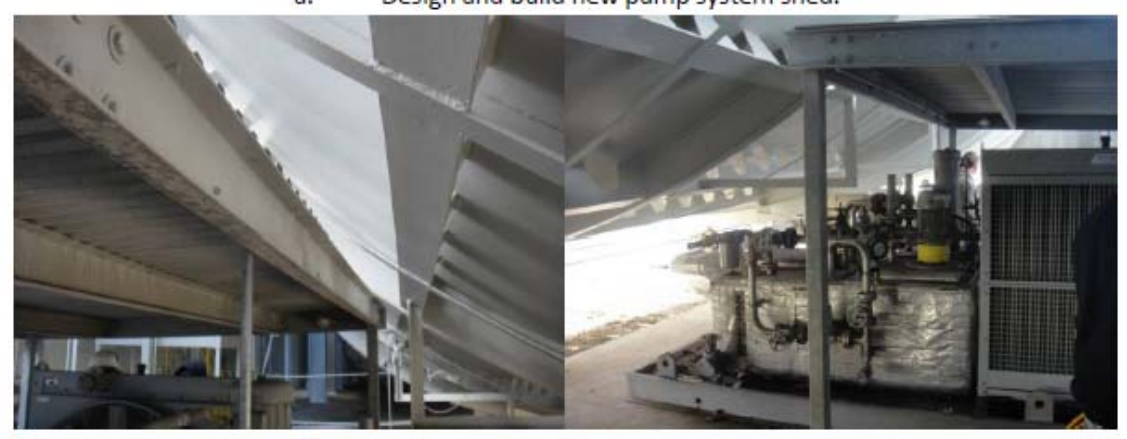

The current shed does not prevent rain water from entering the oil catch pan during rain events. Water runs down the side of the tunnel as well as off of the shed roof into the pan.

American Institute of Aeronautics and Astronautics 


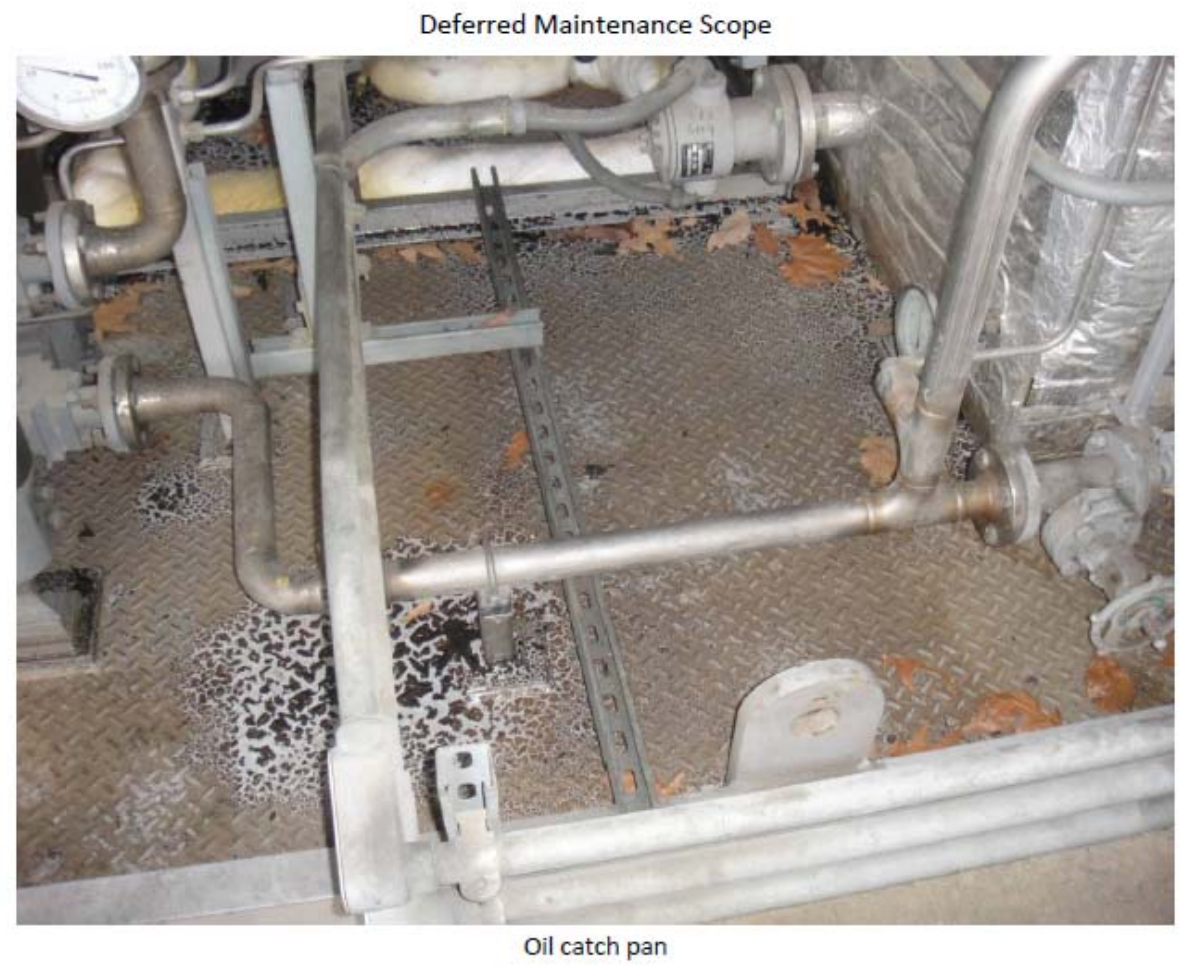

b. Design and install a frame to secure filter material to the air intake tower

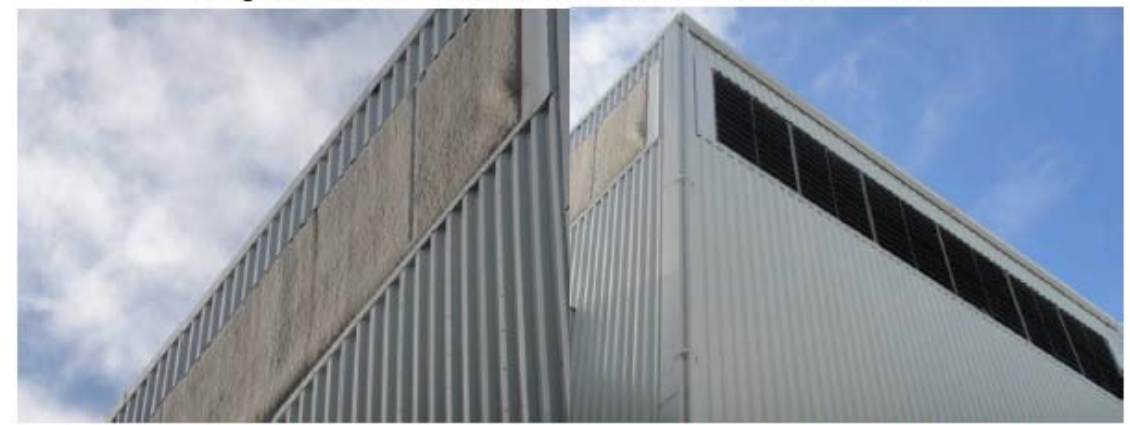

Existing filter material

Intake with missing filter material 


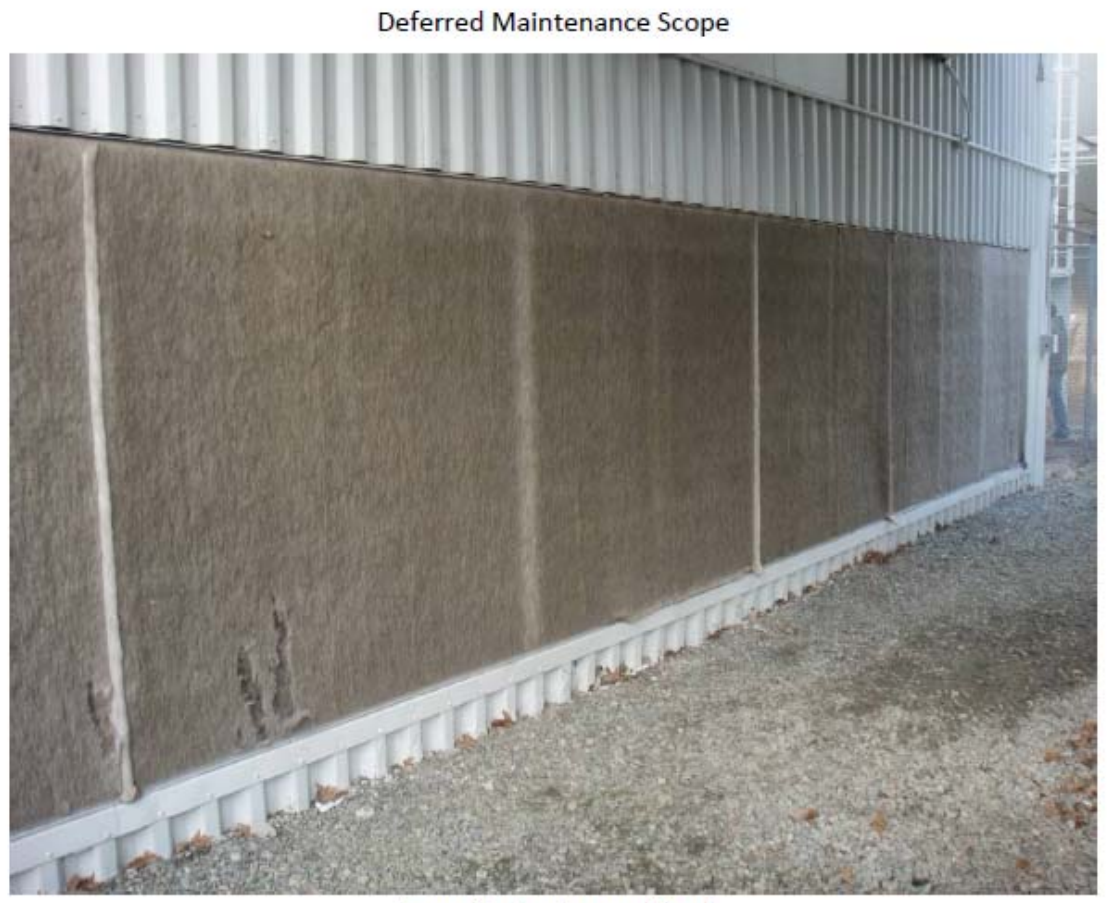

Lower intake at ground level

\section{D: ESTIMATE:}

- Redesign lube pump shed $=\$ 8,000$

- Design catwalk for air intake tower filter access $=\$ 50,000$

\section{E: Points of contact}

\section{APPROVALS}

\begin{tabular}{|c|c|c|}
\hline Prepared By: & S. A. Vaughan & Date: \\
\hline Reviewed By: & K. F. Rubert & Date: \\
\hline
\end{tabular}




\section{Appendix 4}

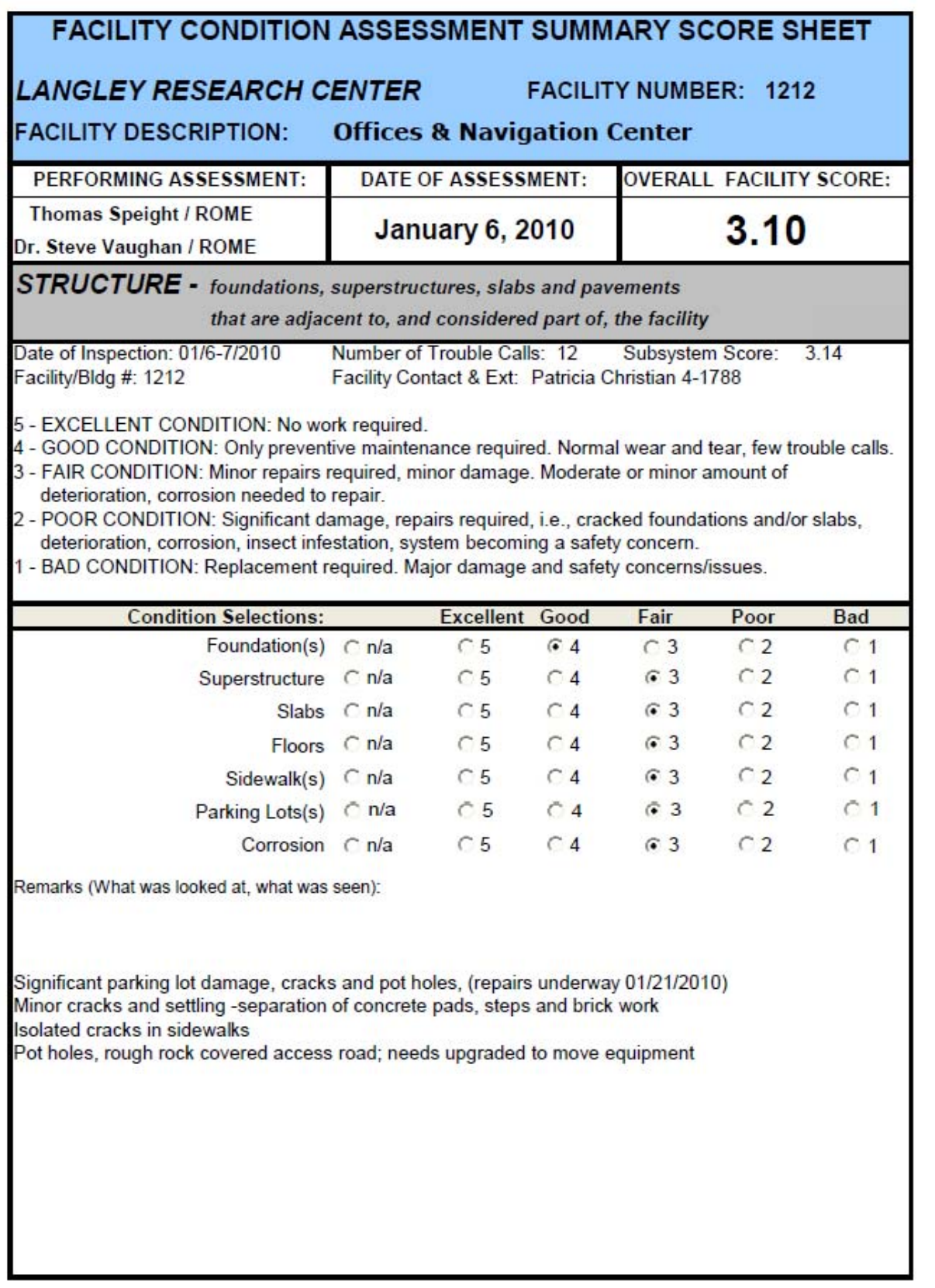




\begin{tabular}{|c|c|c|}
\hline \multicolumn{3}{|c|}{ FACILITY CONDITION ASSESSMENT SUMMARY SCORE SHEET } \\
\hline \multicolumn{3}{|c|}{$\begin{array}{l}\text { LANGLEY RESEARCH CENTER } \quad \text { FACILITY NUMBER: } 1212 \\
\text { FACILITY DESCRIPTION: } \quad \text { Offices \& Navigation Center }\end{array}$} \\
\hline PERFORMING ASSESSMENT: & DATE OF ASSESSMENT: & OVERALL FACILITY SCORE \\
\hline Thomas Speight / ROME & January 6, 2010 & 3.10 \\
\hline
\end{tabular}

ROOFING - Flashing, roof coverings, of, openings

pitch pockets, gutters

Date of Inspection: 1/06/10 Number of Trouble Calls: 3 Subsystem Score: 2.75

Facility/Bldg \#: $1212 \quad$ Facility Contact \& Ext: Patricia Christian 4-1788

5 - EXCELLENT CONDITION: No work required

4 - GOOD CONDITION: Only preventive maintenance required. Minor wear and tear. Minor noticeable deterioration. No leaks. Few trouble calls.

3 - FAIR CONDITION: Minor repairs required for damage. Minor corrosion and loose flashing; roof alligatoring, cracking, some exposed bituminous materials.

- POOR CONDITION: Significant repairs required for damage. Severe corrosion and excessively

loose or cracked flashing; severe roof alligatoring, cracking, exposed bituminous materials; minor leaks.

- BAD CONDITION: Replacement required. Major concerns/issues. Extreme deterioration, severe roof leaks.

\begin{tabular}{|c|c|c|c|c|c|c|}
\hline Condition Selections: & & Excellent & Good & Fair & Poor & Bad \\
\hline Roof Coverings & $\sim \mathrm{n} / \mathrm{a}$ & $\ulcorner 5$ & $\ulcorner 4$ & • 3 & $\sim 2$ & ○ 1 \\
\hline Openings & $\subset \mathrm{n} / \mathrm{a}$ & $\curvearrowright 5$ & $C_{4}$ & $\subset 3$ & $\cdot 2$ & ○ 1 \\
\hline Gutters & $\subset \mathrm{n} / \mathrm{a}$ & $\curvearrowright 5$ & $C_{4}$ & ( 3 & $\ulcorner 2$ & ○ 1 \\
\hline Flashing & $\subset \mathrm{n} / \mathrm{a}$ & $\ulcorner 5$ & $C_{4}$ & • 3 & $\sim 2$ & ○ 1 \\
\hline
\end{tabular}

Remarks (What was looked at, what was seen):

Leaks reported in roof associated with rooms 102, 103, 104, 105 and 116; flashing cracks

Leaks around roof drains noted

Courtyard drain plugged with sand, rocks; etc. 


\section{References}

${ }^{1}$ Fox, M., “NASA’s outdated labs jeopardize research”, Reuters, 5/11/2010.

${ }^{2}$ NASA Reliability Centered Building and Equipment Acceptance Guide, July 2004; NASA Reliability Centered Maintenance Guide for Facilities and Collateral Equipment, September 2008.

${ }^{3}$ Smith, A. M. and Hinchcliffe G. R., RCM-Gateway to World Class Maintenance, Butterworth-Heinemann, Woburn, MA 2003, p. 63.

${ }^{4}$ January 2010 FCA/RCM report for LaRC buildings 1212 and 1212C. 